Tohoku J. Exp. Med., 2007, 212, 397-402

\title{
The Altered Autonomic Nervous System Activity in Iron Deficiency Anemia
}

\author{
Mehmet Yokusoglu, ${ }^{1}$ Oral Nevruz, ${ }^{2}$ Oben Baysan, ${ }^{1}$ Mehmet Uzun, ${ }^{1}$ \\ Sait Demirkol, ${ }^{1}$ Ferit Avcu, ${ }^{2}$ Cem Koz, ${ }^{1}$ Turker Çetin, ${ }^{2}$ Adnan Hasimi, ${ }^{3}$ \\ Ali UGUR UraL ${ }^{2}$ and ERsoy IsIK ${ }^{1}$ \\ ${ }^{1}$ Department of Cardiology, Gulhane Military Medical School, Ankara, Turkey \\ ${ }^{2}$ Department of Hematology, Gulhane Military Medical School, Ankara, Turkey \\ ${ }^{3}$ Department of Clinical Biochemistry, Gulhane Military Medical School, Ankara, Turkey
}

Yokusoglu, M., Nevruz, O., Baysan, O., Uzun, M., Demirkol, S., Avcu, F., Koz, C., Çetin, T., Hasimi, A., Ural, A.U. and Isik, E. The Altered Autonomic Nervous System Activity in Iron Deficiency Anemia. Tohoku J. Exp. Med., 2007, 212 (4), 397-402 Autonomic function is impaired in anemic patients with various etiologies such as vitamin B12 deficiency, sickle cell trait, and thalassemia major. However, there are insufficient data about autonomic functions in patients with iron deficiency anemia, the leading cause for anemia in the general population. In the present study we aimed to investigate the autonomic status in iron deficiency anemia by analyzing the heart rate variability (HRV). Age- and gender-matched 43 patients with iron deficiency anemia and 39 healthy subjects were undertaken into 24-hr Holter monitoring for assessing the HRV. We used serum levels of iron, iron binding capacity, C-reactive protein, vitamin B12, and folate to exclude other causes of anemia. While age, gender, vitamin B12 and folate levels were not different between the groups, HRV values were lower in patients with iron deficiency anemia compared to control group, which reflects parasympathetic withdrawal. Blood hemorheological factors such as decreased viscosity and/or altered red cell deformability may be responsible for this decreased parasympathetic activity. However, these components do not display remarkable contribution in iron deficiency anemia. Therefore, we speculated a probable link between anemia and the accentuated sympathetic activity that may be triggered by hypoxia sensed through carotid bodies. Despite lacking adequate convincing evidence concerning exact mechanism of carotid body activation, it is assumed as due either to hypoxia-related mitochondrial respiratory chain inhibition or potassium channel suppression that leads to intracellular calcium accumulation. In conclusion, the present study demonstrates an altered autonomic balance in patients with true iron deficiency anemia.

- anemia; iron deficiency; heart rate variability; autonomic functions

(C) 2007 Tohoku University Medical Press

Cardiac autonomic functions have been demonstrated to be impaired in various disorders including heart failure (Saul et al. 1988), diabetes mellitus (Freeman et al. 1991) and acute myocardial infarction (Casolo et al. 1992). Although heart rate variability (HRV), the degree of fluctua-

Received February 19, 2007; revision accepted for publication June 20, 2007.

Correspondence: Mehmet Yokusoglu, M.D., Department of Cardiology, Gulhane Military Medical School, 06018 Etlik, Ankara, Turkey.

e-mail: myokusoglu@gata.edu.tr 
tion of the beat-to-beat differences in cardiac rhythm, is an indirect method for cardiac autonomic function determination, it has extensively been used for that purpose as a reliable and noninvasive tool.

Recent advances in technology have provided us more accurate data information via automated analysis of 24-hr electrocardiography (ECG) (Task Force of the European Society of Cardiology the North American Society of Pacing Electrophysiology 1996). HRV parameters can be obtained with time domain, spectral domain, non-linear and mathematical modeling methods. It shows a circadian variation being maximal during sleep (Malpas and Purdie 1990) decreasing with age (O'Brien et al. 1986). The loss of this beat-to-beat variability may be indicative of disease process (Freeman et al. 1991; Odemuyiwa et al. 1991; Ponikowski et al. 1997).

Cardiac autonomic function-anemia relationship has been studied in various anemic patient populations including vitamin $\mathrm{B}_{12}$ deficiency (Sozen et al. 1998), sickle cell anemia (Romero Mestre et al. 1997) and thalassemia major (Veglio et al. 1998; Franzoni et al. 2004). The results of these studies have implied that cardiac autonomic functions are impaired in anemia. However, the predominant cause of anemia in general population, by far, is iron deficiency and there are little data about cardiac autonomic functions in anemic patients due to this condition.

This cross-sectional study is designed for detecting the autonomic status of patients with iron deficiency anemia by using time domain analysis of heart rate variability.

\section{Material and Methods}

Forty-three consecutive patients with iron deficiency anemia (Male/Female ratio: 15/28, mean age: $34 \pm 4$ years) comprised the study group. The control group was composed of age and gender-matched 39 healthy subjects (Male/Female ratio: 14/25, mean age: $32 \pm 8$ years). Any subject with vitamin $B_{12}$ or folate deficiency, sickle cell disease, thalassemia, diabetes and coronary artery disease were excluded from the study. The study protocol was reviewed and approved by local ethics committee of Gulhane Military Medical School, and all par- ticipants signed written informed consent.

\section{Diagnosis of iron deficiency anemia}

The diagnosis of anemia was made according to complete blood count (Cell-Dyne 4000 cell counter; Abbott Laboratories, Abbott Park, IL, USA), serum ferritin, vitamin $B_{12}$ and folate levels those carried out by using E 170 module for Modular Analytics-E170 and original material manifactured for this device (Roche Diagnostics GmmH, Mannheim, Germany). Apart from low serum ferritin levels, whole blood hemoglobin values below $11.7 \mathrm{~g} / \mathrm{dl}$ for females and $13 \mathrm{~g} / \mathrm{dl}$ for males were regarded as satisfactory criteria for the diagnosis of iron deficiency anemia. We used serum iron, serum iron binding capacity and C-reactive protein levels for excluding the patients with other causes of anemia.

\section{$H R V$}

Twenty-four-hr ambulatory electrocardiographic recordings were obtained from each subject with Rozinn RZ 152 digital holter recorder (Rozinn Electronics, Inc., Glendale, NY, USA) with the sampling frequency of $1,024 \mathrm{~Hz}$. All cases were strictly advised to maintain the normal course of their daily life. Their obedience to this advice was confirmed again while removing the device from the cases. Any medication was stopped at least one week prior to Holter ECG examination. The HRV was determined by the software of the same device. Due to technical limitations in analysis software, only the timedomain indices of HRV from a 24-hr recording were calculated.

The time domain HRV parameters that measured in our study were the standard deviation of all normal sinus R-R intervals over $24 \mathrm{hrs}$ (SDNN), the standard deviation of all averaged normal sinus R-R intervals for each 5-min segment in the 24-hr recordings (SDANN), root mean square of successive differences between normal sinus R-R intervals (RMSSD), the ratio of number of all $\mathrm{R}-\mathrm{R}$ intervals to the height of histogram created by the charting all the RR intervals (HRV triangular index), number of R-R intervals exceeding $50 \mathrm{msec}$ (SNN50 count), the percentage of difference between adjacent normal R-R intervals that are greater than $50 \mathrm{msec}$ computed over the entire 24-hr ECG recording (PNN50).

In addition to HRV variables, basic rhythm and associated disturbances such as atrial or ventricular arrhythmias were also carefully evaluated. 


\section{Statistical analysis}

Comparisons between the groups were carried out with 2-tailed Student's $t$-test for normally distributed continuous variables, Mann-Whitney's U-test for data without normal distribution and chi-square test for dichotomous variables. A $p$ value below 0.05 was set significant.

\section{Results}

There were no statistically significant differences between the study group and the control group in relation to age and gender (Table 1). All subjects were detected to be in sinus rhythm without episodes of sustained atrial or ventricular arrhythmias. Mean heart rate was significantly higher and mean hemoglobin, hematocrit, and ferritin levels were significantly lower in the study group in comparison with the control group as expected (Table 1). Any evidence regarding a malignancy was not noted in participant due to clinical and laboratory examination results and there was no difference between male and females with regard to demographic, clinical and laboratory parameters in both groups.

TABLE 1. Demographic and clinical characteristics of subjects and comparison of study and control groups.

\begin{tabular}{lccc}
\hline \multicolumn{1}{c}{ Characteristics } & $\begin{array}{c}\text { Study group } \\
(n=43)\end{array}$ & $\begin{array}{c}\text { Control group } \\
(n=39)\end{array}$ & $p$ value \\
\hline Age (years) & $34 \pm 4$ & $32 \pm 8$ & NS \\
Gender & & & \\
Male & $15(35 \%)$ & $14(36 \%)$ & $\mathrm{NS}$ \\
Female & $28(65 \%)$ & $25(64 \%)$ & \\
Heart rate (bpm) & $117 \pm 19$ & $78 \pm 17$ & $<0.05$ \\
Hb values (g/dl) & $8.9 \pm 2.1$ & $13.1 \pm 0.4$ & $<0.05$ \\
Hct values $(\%)$ & $29.1 \pm 1.1$ & $40.2 \pm 3.1$ & $<0.05$ \\
MCV (fl) & $69.2 \pm 2.1$ & $84.3 \pm 2.4$ & $<0.05$ \\
Serum ferritin values $(\mathrm{ng} / \mathrm{ml})$ & $5.3 \pm 0.2$ & $98 \pm 7.1$ & $<0.05$ \\
Vit $\mathrm{B}_{12}$ levels $(\mathrm{pg} / \mathrm{ml})$ & $249 \pm 65$ & $276 \pm 72$ & $\mathrm{NS}$ \\
Folate $(\mathrm{ng} / \mathrm{ml})$ & $6.1 \pm 1.2$ & $7 \pm 1.9$ & $\mathrm{NS}$ \\
\hline
\end{tabular}

$n$, number of cases; Hb, hemoglobin; Hct, Hematocrit; NS, not significant.

TABLE 2. Statistical comparison of HRV variables of study and control groups.

\begin{tabular}{lccc}
\hline & Study group & Control group & $p$ value \\
\hline SDNN (msec) & $118 \pm 36$ & $139 \pm 42$ & $<0.05$ \\
SDANN (msec) & $98 \pm 33$ & $120 \pm 37$ & $<0.05$ \\
RMSSD (msec) & $24 \pm 13$ & $29 \pm 11$ & $=0.26$ \\
HRV-Triangular Index & $31 \pm 9$ & $35 \pm 10$ & $=0.09$ \\
SNN50 Count & $6,301 \pm 7,673$ & $15,428 \pm 4,210$ & $<0.05$ \\
PNN50 $(\%)$ & $14 \pm 4$ & $23 \pm 7$ & $<0.05$ \\
\hline
\end{tabular}

SDNN, the standard deviation of all normal sinus R-R intervals over $24 \mathrm{hrs;} \mathrm{SDANN,} \mathrm{the} \mathrm{standard}$ deviation of all averaged normal sinus R-R intervals for each 5-min segment in the 24-hr recordings; RMSSD, root mean square of successive differences between normal sinus R-R intervals; HRV triangular index, the ratio of number of all R-R intervals to the height of histogram created by the charting all the RR intervals; SNN50 count, number of R-R intervals exceeding 50 msec; PNN50, the percentage of difference between adjacent normal $\mathrm{R}-\mathrm{R}$ intervals that are greater than $50 \mathrm{msec}$ computed over the entire 24-hr ECG recording. 
The statistical comparisons of HRV parameters are presented in Table 2. All time domain indices of HRV except RMSSD and HRVtriangular index showed statistically significant decrease in patients compared to control group.

\section{Discussion}

The main result of the present study was an alteration in HRV parameters of patients with iron deficiency anemia. The imbalance between sympathetic and parasympathetic nerve activities can disturb electrophysiologic properties of the heart and may probably lead to increased mortality. Indeed, decrease in HRV was suggested to predict coronary heart disease morbidity and mortality in patients after an acute coronary event (Odemuyiwa et al. 1991). Moreover, HRV parameters were found to be altered in various disorders such as diabetic neuropathy (Kitney et al. 1982), heart failure (Saul et al. 1988), acute leukemias (Nevruz et al. 2007), allergic rhinitis (Yokusoglu et al. 2007), fetal type Minamata disease (Oka et al. 2002), in preschool children with short nocturnal sleep (Sampei et al. 2006), primary nocturnal enuresis (Dundaroz et al. 2001; Unalacak et al. 2004), following a cardiac transplantation (Sands et al. 1989) or cardiac resynchronization therapy (Akyol et al. 2006) and during adrenocorticotropic hormone replacement treatment in infants with West syndrome (Hattori et al. 2007).

Veglio et al. (1998) reported decreased sympathetic activity in patients with thalassemia major. However, in that, study investigators evaluated the HRV at 2 to 5 days after transfusion and hemoglobin levels of the subjects were all in normal range. Similar decrease in time-domain parameters of HRV was also detected in nonanemic sickle cell trait carriers (Connes et al. 2006). In contrast to these results anemic patients have low parasympathetic activity (Lakhotia et al. 1996) and all these findings may indicate that autonomic dysfunction is not dependent on the presence of anemia. Moreover, both sympathetic and parasympathetic components of HRV were significantly lower in anemic patients with vitamin $B_{12}$ deficiency (Sozen et al. 1998) which may suggest that anemia itself may be a cause of auto- nomic dysfunction. Gehi et al. (2005) also stated that anemia-low HRV association was still strong enough after adjustment of other factors such as left ventricular mass and ejection fraction in stable coronary artery disease patients Degree of anemia was suggested to correlate with the progression of autonomic dysfunction in anemic patients with familial amyloidotic polyneuropathy (Asahara et al. 1993). Furthermore, elevations in plasma catecholamine and $\alpha_{2}$-receptor density levels as previously reported by Muller et al. (1991) also support the high sympathetic activity in anemic patients.

We detected an impairment in global (SDNN, SDANN) indices of HRV that might be caused by increased sympathetic or decreased parasympathetic activity. Another global parameter, HRV triangular index, was also lower in the study group but not reached statistical significance. This index is mainly affected by lower frequencies which reflect the dominance of sympathetic activity (Malik et al. 1989). Therefore, in the light of decreased parasympathetic activity indices of HRV (RMSSD, PNN50) we speculated that sympathetic activity is dominant in patients with iron deficiency anemia. Connes et al. (2006) attributed these autonomic changes to altered hemorheological factors such as blood viscosity and red blood cell deformability in sickle cell trait carriers. Red cell deformability in iron deficient state is a controversial issue. While Tilmann and Schroter (1980) and Vaya et al. (2005) reported decreased erythrocyte deformability, some other authors stating normal values (Reinhart 1992). Moreover iron deficiency has no effect on blood viscosity even in patients with cyanotic heart diseases (Broberg et al. 2006). An explanation for autonomic dysfunction in iron deficiency anemia can be low oxygen tension in tissues. Hypoxia has an important pathophysiologic role in various disease states including anemia (Zhu et al. 2002). Although how low oxygen tension sensed by the cell is not clear, carotid body with resulting ventilatory and cardiovascular reflexes seems to has a major role in altered autonomic balance (Schultz and Sun 2000; Lahiri et al. 2006). Despite lacking adequate convincing evidence concerning 
exact mechanism of carotid body activation, it is assumed as due either to hypoxia-related mitochondrial respiratory chain inhibition or potassium channel suppression which lead to intracellular calcium accumulation (Lahiri et al. 2006).

\section{Limitations}

The absence of patients with iron deficiency but not in anemic state should be interpreted as major limitation of the study. Interpretation of HRV indices in this group of patients may have been used for better delineation of anemia-autonomic dysfunction relation. However, there are no data in literature suggesting deteriorated autonomic functions in non-anemic iron deficiency patients and hence this question needs to be answered by further studies.

We have only been able to use the timedomain parameters of HRV for technical reasons. If frequency-domain parameters would have been included, the study may be more informative. However, we think that the study is still valuable because time-domain and frequency-domain parameters are related to each other. A change in one of them is generally suggestive of a change in the other (Vaishnav et al. 1994).

\section{Future expectations}

We found sympathetic dominance in iron deficiency anemia, which may be in association with the cardiovascular disease and arrhythmic death in future life of these patients. This hypothesis should be searched in future mortality and morbidity studies.

\section{References}

Akyol, A., Alper, A.T., Cakmak, N., Hasdemir, H., Eksik, A., Oguz, E., Erdinler, I., Ulufer, F.T. \& Gurkan, K. (2006) Long-term effects of cardiac resynchronization therapy on heart rate and heart rate variability. Tohoku J. Exp. Med., 209, 337-346.

Asahara, K., Ando, Y., Tanaka, Y., Yi, S., Yamashita, T. \& Ando, M. (1993) Secondary hypoplastic anemia in patients with familial amyloidotic polyneuropathy. Acta Haematol., 90, 130-135.

Broberg, C.S., Bax, B.E., Okonko, D.O., Rampling, M.W., Bayne, S., Harries, C., Davidson, S.J., Uebing, A., Khan, A.A., Thein, S., Gibbs, J.S., Burman, J. \& Gatzoulis, M.A. (2006) Blood viscosity and its relationship to iron deficiency, symptoms, and exercise capacity in adults with cya- notic congenital heart disease. J. Am. Coll. Cardiol., 48, 356-365.

Casolo, G.C., Stroder, P., Signorini, C., Calzolari, F., Zucchini, M., Balli, E., Sulla, A. \& Lazzerini, S. (1992) Heart rate variability during the acute phase of myocardial infarction. Circulation, 85, 2073-2079.

Connes, P., Martin, C., Barthelemy, J.C., Monchanin, G., Atchou, G., Forsuh, A., Massarelli, R., Wouassi, D., Thiriet, P. \& Pichot, V. (2006) Nocturnal autonomic nervous system activity impairment in sickle cell trait carriers. Clin Physiol Funct Imaging, 26, 87-91.

Dundaroz, M.R., Denli, M., Uzun, M., Aydin, H.I., Sarici, S.U., Yokusoglu, M. \& Ulgen, S. (2001) Analysis of heart rate variability in children with primary nocturnal enuresis. Int. Urol. Nephrol., 32, 393-397.

Franzoni, F., Galetta, F., Di Muro, C., Buti, G., Pentimone, F. \& Santoro, G. (2004) Heart rate variability and ventricular late potentials in beta-thalassemia major. Haematologica, 89, 233-234.

Freeman, R., Saul, J.P., Roberts, M.S., Berger, R.D., Broadbridge, C. \& Cohen, R.J. (1991) Spectral analysis of heart rate in diabetic autonomic neuropathy. A comparison with standard tests of autonomic function. Arch. Neurol., 48, 185-190.

Gehi, A., Ix, J., Shlipak, M., Pipkin, S.S. \& Whooley, M.A. (2005) Relation of anemia to low heart rate variability in patients with coronary heart disease (from the Heart and Soul study). Am. J. Cardiol., 95, 1474-1477.

Hattori, A., Hayano, J., Fujimoto, S., Ando, N., Mizuno, K., Kamei, M., Kobayashi, S., Ishikawa, T. \& Togari, H. (2007) Cardiac vagal activation by adrenocorticotropic hormone treatment in infants with West syndrome. Tohoku J. Exp. Med., 211, 133-139.

Kitney, R.I., Byrne, S., Edmonds, M.E., Watkins, P.J. \& Roberts, V.C. (1982) Heart rate variability in the assessment of autonomic diabetic neuropathy. Automedica., 4, 155-167.

Lahiri, S., Roy, A., Baby, S.M., Hoshi, T., Semenza, G.L. \& Prabhakar, N.R. (2006) Oxygen sensing in the body. Prog. Biophys. Mol. Biol., 91, 249-286.

Lakhotia, M., Shah, P.K., Gupta, A., Jain, S.S., Agarwal, M. \& Dadhich, S. (1996) Clinical assessment of autonomic functions in anemics. J. Assoc. Physicians India, 44, 534-536.

Malik, M., Farrell, T., Cripps, T. \& Camm, A.J. (1989) Heart rate variability in relation to prognosis after myocardial infarction: selection of optimal processing techniques. Eur. Heart J., 10, 1060-1074.

Malpas, S.C. \& Purdie, G.L. (1990) Circadian variation of heart rate variability. Cardiovasc. Res., 24, 210-213.

Muller, R., Steffen, H.M., Brunner, R., Saric, J., Pollok, M., Baldamus, C.A. \& Kaufmann, W. (1991) Changes in the alpha adrenergic system and increase in blood pressure with recombinant human erythropoietin (rHuEpo) therapy for renal anemia. Clin. Invest. Med., 14, 614-622.

Nevruz, O., Yokusoglu, M., Uzun, M., Demirkol, S., Avcu, F., Baysan, O., Koz, C., Cetin, T., Sag, C., Ural, A.U. \& Isik, E. (2007) Cardiac autonomic functions are altered in patients with acute leukemia, assessed by heart rate variability. Tohoku J. Exp. Med., 211, 121-126.

O’Brien, I.A., O’Hare, P. \& Corrall, R.J. (1986) Heart rate variability in healthy subjects: effect of age and the derivation of normal ranges for tests of autonomic function. Br. Heart $J ., 55,348-354$.

Odemuyiwa, O., Malik, M., Farrell, T., Bashir, Y., Poloniecki, J. 
\& Camm, J. (1991) Comparison of the predictive characteristics of heart rate variability index and left ventricular ejection fraction for all-cause mortality, arrhythmic events and sudden death after acute myocardial infarction. Am. J. Cardiol., 68, 434-439.

Oka, T., Matsukura, M., Okamoto, M., Harada, N., Kitano, T., Miike, T. \& Futatsuka, M. (2002) Autonomic nervous functions in fetal type Minamata disease patients: assessment of heart rate variability. Tohoku J. Exp. Med., 198, 215-221.

Ponikowski, P., Anker, S.D., Chua, T.P., Szelemej, R., Piepoli, M., Adamopoulos, S., Webb-Peploe, K., Harrington, D., Banasiak, W., Wrabec, K. \& Coats, A.J. (1997) Depressed heart rate variability as an independent predictor of death in chronic congestive heart failure secondary to ischemic or idiopathic dilated cardiomyopathy. Am. J. Cardiol., 79, 1645-1650.

Reinhart, W.H. (1992) The influence of iron deficiency on erythrocyte deformability. Br. J. Haematol., 80, 550-555.

Romero Mestre, J.C., Hernandez, A., Agramonte, O. \& Hernandez, P. (1997) Cardiovascular autonomic dysfunction in sickle cell anemia: a possible risk factor for sudden death? Clin. Auton. Res., 7, 121-125.

Sampei, M., Murata, K., Dakeishi, M. \& Wood, D.C. (2006) Cardiac autonomic hypofunction in preschool children with short nocturnal sleep. Tohoku J. Exp. Med., 208, 235-242.

Sands, K.E., Appel, M.L., Lilly, L.S., Schoen, F.J., Mudge, G.H., Jr. \& Cohen, R.J. (1989) Power spectrum analysis of heart rate variability in human cardiac transplant recipients. Circulation, 79, 76-82.

Saul, J.P., Arai, Y., Berger, R.D., Lilly, L.S., Colucci, W.S. \& Cohen, R.J. (1988) Assessment of autonomic regulation in chronic congestive heart failure by heart rate spectral analysis. Am. J. Cardiol., 61, 1292-1299.

Schultz, H.D. \& Sun, S.Y. (2000) Chemoreflex function in heart failure. Heart Fail Rev., 5, 45-56.

Sozen, A.B., Demirel, S., Akkaya, V., Kudat, H., Tukek, T., Yeneral, M., Ozcan, M., Guven, O. \& Korkut, F. (1998) Autonomic dysfunction in vitamin B12 deficiency: a heart rate variability study. J. Auton Nerv. Syst., 71, 25-27.

Task Force of the European Society of Cardiology the North American Society of Pacing Electrophysiology (1996) Heart Rate Variability. Standards of Measurement, Physiological Interpretation, and Clinical Use. Circulation, 93, 1043-1065.

Tillmann, W. \& Schroter, W. (1980) Deformability of erythrocytes in iron deficiency anemia. Blut, 40, 179-186.

Unalacak, M., Aydin, M., Ermis, B., Ozeren, A., Sogut, A., Demirel, F. \& Unluoglu, I. (2004) Assessment of cardiac autonomic regulation in children with monosymptomatic nocturnal enuresis by analysis of heart rate variability. Tohoku J. Exp. Med., 204, 63-69.

Vaishnav, S., Stevenson, R., Marchant, B., Lagi, K., Ranjadayalan, K. \& Timmis, A.D. (1994) Relation between heart rate variability early after acute myocardial infarction and longterm mortality. Am. J. Cardiol., 73, 653-657.

Vaya, A., Simo, M., Santaolaria, M., Todoli, J. \& Aznar, J. (2005) Red blood cell deformability in iron deficiency anaemia. Clin. Hemorheol. Microcirc., 33, 75-80.

Veglio, F., Melchio, R., Rabbia, F., Molino, P., Genova, G.C., Martini, G., Schiavone, D., Piga, A. \& Chiandussi, L. (1998) Blood pressure and heart rate in young thalassemia major patients. Am. J. Hypertens., 11, 539-547.

Yokusoglu, M., Ozturk, S., Uzun, M., Baysan, O., Demirkol, S., Caliskaner, Z., Dundaroz, R., Sag, C., Karaayvaz, M. \& Isik, E. (2007) Heart rate variability in patients with allergic rhinitis. Mil. Med., 172, 98-101.

Zhu, H., Jackson, T. \& Bunn, H.F. (2002) Detecting and responding to hypoxia. Nephrol. Dial Transplant., 17, Suppl. 1, 3-7. 